\title{
Strategic Price Discrimination in Compulsory Insurance Markets
}

\author{
LUIGI BUZZACCHI \\ luigi.buzzacchi@polito.it \\ Politecnico di Torino and CERAP-Università Bocconi, DSPEA, Corso Duca degli Abruzzi 24, 10129 Torino, Italy \\ TOMMASO M. VALLETTI \\ t.valletti@ic.ac.uk,www.imperial.ac.uk/people/t.valletti \\ Imperial College London and CEPR, Tanaka Business School, South Kensington Campus, London SW7 2AZ, UK
}

Received December 4, 2003; Revised August 31, 2004

\begin{abstract}
This paper considers price discrimination when competing firms do not observe a customer's type but only some other variable correlated to it. This is a typical situation in many insurance markets-such as motor insurancewhere it is also often the case that insurance is compulsory. We characterise the equilibria and their welfare properties under various price regimes. We show that discrimination based on immutable characteristics such as gender is a dominant strategy, either when firms offer policies at a fixed price or when they charge according to some consumption variable that is correlated to costs. In the latter case, gender discrimination can be an outcome of strategic interaction alone in situations where it would not be adopted by a monopolist. Strategic price discrimination may also increase cross subsidies between types, contrary to expectations.
\end{abstract}

Key words: price discrimination, insurance classification, equity, variable insurance charges

JEL Classification No.: L13, G22

\section{Introduction}

The chapter on the theory of classification in the recent Handbook of Insurance, begins by stating that "the efficiency and equity effects of risk classification in insurance markets have been a source of substantial debate amongst economists and in the public policy area" [Crocker and Snow, 2000]. Most of the literature refers to polar cases of market structure, either monopoly or perfect competition, where demand for insurance is elastic and where there are no constraints on classification parameters that firms may want to adopt. In such settings, the efficiency and equity properties of classification depend on the type of informational asymmetries between the firms and their customers. When the information about the expected costs of insured customers is perfect, then it is possible to assess the precise cost of each insured category. If such information is not available on either side of the market, then a competitive market would pool all the risks and achieve an (information-constrained) efficient allocation. If, on the other hand, firms have some extra information at their disposal (e.g., they observe some parameter correlated to risk), then the market would achieve an (ex ante) inferior allocation in the presence of risk-averse customers since firms would use such additional information and customers would bear the 
associated classification risk. Finally, if customers have better information about their risk than the firms, pooling equilibria may not exist, adverse selection phenomena arise, and risk classification would increase allocative efficiency [Crocker and Snow, 1986]. ${ }^{1}$

This paper reconsiders the problem of risk classification when firms do not observe a customer's type but only some other variable correlated to it. In some contrast with the previous literature, we do not focus on the adverse selection problem since we consider a market that is always fully covered. Coverage here refers both to the participation decision of a consumer, and to the reimbursement of losses. In our model insurance is compulsory by law, hence there is "full coverage" in the sense of full market participation. Losses are also completely reimbursed after an accident occurs, hence the insured person is "fully covered" against losses, i.e. there is no risk sharing between the insurer and its customers.

These assumptions clearly depart from typical models of insurance that have studied how classification can be used to improve allocations in the presence of adverse selection. However, we discuss below that they have some important empirical justifications, e.g. compulsory third-party liability in car insurance. This assumption implies that one of the major reasons for advocating classification, i.e. the reduction of adverse selection, does not play a role in our model. While we considerably simplify in some directions, we can concentrate on other aspects that have not been fully investigated in the traditional literature. In particular, we study the strategic interaction between imperfectly competitive firms that may decide whether to adopt classification variables. The literature on risk classification has not dealt in depth with oligopolistic situations, despite the fact that these are common market structures. ${ }^{2}$ Moreover, the efficiency properties are typically characterised for symmetric equilibria, while it is less clear if firms would have a unilateral incentive to adopt a particular pricing strategy. In this respect, we draw from a different stream in the IO literature on price discrimination in oligopolies that has recently received considerable attention [see Stole, 2001, for a survey].

We introduce a stylised model to describe an imperfectly competitive market with compulsory insurance. Third-party liability in car insurance is our motivating example. In our model, we have two types of customers (high- and low-cost) who have private information about their type. Types differ in their willingness-to-travel, although their unit cost (cost per mile travelled) is identical. Higher types travel more than lower types at a given price, hence their total cost is also higher. Types are not observed directly by two imperfectly competitive firms, that can, on the other hand, observe gender, a publicly-observable attribute. Gender is an immutable characteristic that is only statistically correlated with types, and hence informative about an individual's underlying cost. In particular, men on average travel more (hence they are "riskier") than women, but a significant portion of men are low risk. When firms offer policies at a fixed price (i.e., mile independent), consumption of each type is not affected by prices (consumers effectively face a zero marginal insurance price in their mile consumption choices); discrimination over the immutable characteristic is clearly motivated by the fact that classification alters the expected cost to the firm of a certain customer class. This gives an advantage to a "deviant" firm that introduces discrimination when the rival does not discriminate, letting discrimination always emerge in equilibrium. ${ }^{3}$

In our model we also consider classification based on mutable variables. In contrast to immutable characteristics, in many relevant situations the insured person can take some actions 
that are influenced by the classification method. This can happen when the classification variable is correlated with consumption choices. In the anticipation of this, firms themselves may introduce classification aimed at influencing consumption choices (e.g., they may offer discounts if the customer invests in particular technologies that reduce costs). When classification occurs over "mutable" characteristics there will then be additional allocative effects that have to be taken into consideration [Bond and Crocker, 1991].

Categorisation over mutable variable in car insurance can arise when firms implement "Pay-As-You-Drive" pricing (PAYD), i.e. pricing policies that depend on the distance travelled by an insured person. PAYD schemes can be put in practice in different manners, for instance by striking special deals with gasoline stations ("Pay-At-The-Pump"), or with the use of "black boxes" or Global Positioning Systems (GPS). ${ }^{4}$ These technologies allow the insurer to calculate premiums based on how often (and possibly also when, and where) the vehicle is used. These technologies have been around for some time, but only now they have started to emerge as real possibilities. ${ }^{5}$ In our model, when firms charge according to some consumption variable that is correlated to costs (per mile pricing), in principle the firm is already addressing the "true" cause that generates costs (i.e. miles travelled). Still, we show that discrimination based on sex is always a dominant strategy, unless firms can offer fully non-linear contracts over miles.

Our final point of interest in this paper deals with equity which plays an important and controversial role in the policy debate. Equity is somewhat related to the presence of crosssubsidies that would emerge in pooling equilibria when firms do not discriminate among different classes of customers, so that each customer would be charged an average of the costs caused by the pool of customers in place of his actuarially fair price. The presence of cross-subsidies is often seen as something "bad", in the sense that they may induce inefficient allocations and may also result in some degree of inequity since customers would not contribute to cost-recovery according to their "true" cost. On the other hand, Schmalensee [1984] and Hoy and Lambert [2000] discuss the notion that classification is often far from perfect, i.e. it introduces some parameters that are only statistically, but not causally, related to the risk of a given customer. Hence, classification according to "imperfect" variables may end up attributing customers to the wrong classification class (misclassification).

As mentioned above, a real-life case where insurance is compulsory is insurance coverage for auto liability. ${ }^{6}$ Full coverage in terms of participation is thus mandated by law. In terms of risk-sharing, full coverage is also a good approximation of what happens in practice for third-party liability. In Italy, for example, more than $60 \%$ of the insurance companies do not offer deductibles at all on this type of product. The remaining firms offer deductibles in purely nominal terms. For instance, in a random sample of 10,000 contracts that we analyzed, we found only 1 example of a customer taking this option. ${ }^{7}$ In principle, risksharing could also occur along another dimension, namely the sum insured. Also in this case, however, there are regulations that make this aspect irrelevant: in Italy, the minimum limit has to be approximately $\$ 1$ million, which virtually covers all accidents in practice. In this scenario, classification is still very important. Figure 1 illustrates an interesting natural experiment. Car insurance was regulated in Italy until 1994 when the market was liberalised. Before liberalisation, companies were obliged to charge the same prices over the entire 


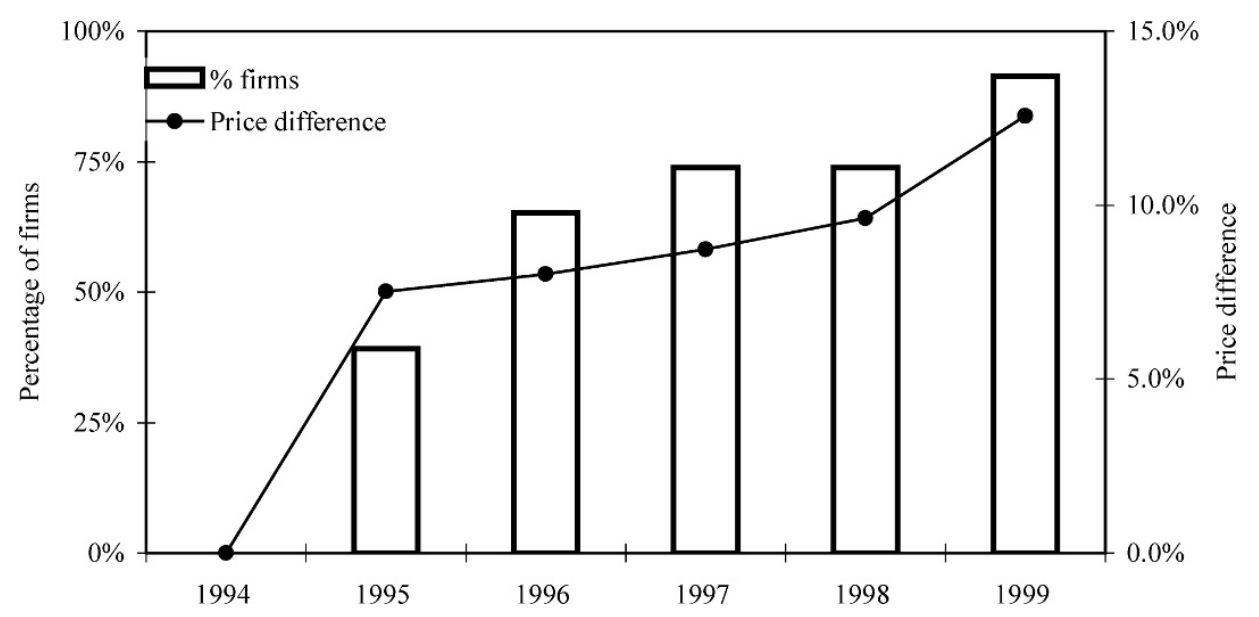

Figure 1. Use of sex discrimination in Italy since liberalisation. ${ }^{8}$

country, using a limited number of parameters. Starting in 1995, companies could charge the prices they wanted in every area. In particular, firms started experimenting with all sorts of classification variables, where sex classification is one of the most adopted and easiest to monitor. The trend that emerges from figure 1 is clear. Three years after liberalisation, $75 \%$ of the firms introduced classification based on sex (left scale). Moreover, the price differences between the sex classes have become more marked (right scale), reflecting the fact that the competitive advantage gained by the first adopters was gradually wiped out by increased competition, so that prices had to reflect the average cost differences between men and women.

To summarize, in this paper we want to characterise the equilibria of a multi-stage game, where firms first decide individually on the type of pricing policy and then compete against a rival. In our model customers are fully insured against losses (there is no choice under uncertainty) and everybody participates (there is no adverse selection problem). In this context, we show how classification is introduced by firms and may affect consumption choices. Once the equilibria are found, we are also interested in their properties, in terms of both efficiency and equity. We do share an interest in the normative question on whether to allow discrimination; however our main goal here is a positive one. We show that price discrimination tends to be introduced quite naturally by firms because of strategic reasons, not necessarily related to its role to improve the information at the firm's disposal. Our results points to this strategic role especially when a clear distinction is drawn between discrimination based on immutable and on mutable variables.

Our results contribute to the theory of oligopolistic price discrimination. They illustrate the point that-as long as firms cannot implement fully non-linear contracts over milesany variable that is just statistically correlated to risk would be introduced by imperfectly competitive firms, despite the fact that such variable may have a very poor informative content. ${ }^{9}$ The use of classification variables arises not just because of the obvious reason 
that it can improve the information at the firm's disposal (as it is in the case of classification over immutable variables), but also because of more subtle strategic reasons. In fact, when firms compete in linear prices, the model that we use implies that customers have the same demand elasticity, hence a monopolist firm would never discriminate over gender when allowed to do so. In an imperfectly competitive framework, however, other factors such as the locational advantage of each firm have an important impact on the customers' subscription choices and this results in the unilateral incentive to introduce class discrimination even when firms directly charge consumption that is correlated to costs. Rather intriguingly, we also show that when discrimination is based on consumption choices (per mile pricing), gender discrimination entails charging the high-cost gender (men) a lower unit premium than the lower-cost type.

Our results should also be seen as a contribution to the insurance literature. We study in a systematic way the incentives that firms have to introduce classification as a function of the type of variable used. We offer a framework that can be used to evaluate the properties of classification in terms of efficiency and equity. We show that the properties are often non-obvious, especially when linear prices are involved, since classification methods in an oligopolistic environment are affected by considerations on demand elasticities that are typically absent in the traditional literature with pure monopoly or perfect competition.

The remainder of the paper is structured as follows. Section 2 describes the main model, while Section 3 characterises its equilibria and their properties when firms offer policies at a fixed price (with and without discrimination over immutable variables). Section 4 addresses the case of discrimination over mutable variables, including both non-linear and linear prices. Section 5 concludes.

\section{The model}

A population of mass one needs compulsory insurance coverage for auto liability. Each person subscribes at most to one policy. Once insured, people differ in their willingness-totravel. In particular, a type- $t$ derives a gross utility from travelling a certain number of miles $m$ equal to $2 \sqrt{\alpha_{t} m}-m$. The implication of a concave utility function of this kind is that people would travel a finite amount of miles, even in the case where there is no insurance fee charged on a per mile basis, with higher types travelling more than low types.

There are two competing firms located at the end points of the Hotelling line of unit length. The cost to an insurance company depends on the probability of an insured person to have an accident and we assume it to be proportional to the number of miles travelled. Let $\theta$ denote the expected unit cost per mile (expected liability damages). There are two types $t=\{h, l\}$, with $\alpha_{h}>\alpha_{l}$, but types cannot be directly observed by firms. What firms can directly observe is another "class" variable $c$ - that we call sex - that is not directly related to risk but is correlated to it, $c=\{$ woman, $\operatorname{man}\}$. We assume that the population is made of a fraction $w$ of women and $1-w$ of men, and that a proportion $y>1 / 2$ of men is of type $h$ while women's $h$-types are only a proportion $1-y$. In other words, men are on average riskier (i.e., they contain more high types than low types) than women. ${ }^{10}$ Customers are distributed uniformly along the Hotelling line. At times it will be convenient to refer to the overall fraction of high types and of low types at each location; these are respectively 
$s_{h}=w(1-y)+(1-w) y=y+w(1-2 y)<y$ and $s_{l}=1-s_{h}$. The proportion of men and women is identical at each point along the line. Customers pay-in addition to the firm's price- a "transport" cost proportional to the distance between the customer's ideal location and the firm they buy from. We denote by $\tau$ the unit "transport" cost. The utility of a type- $t$ customer located at $x$ that buys from firm $i$ located at $x_{i}=\{0,1\}$, that pays a fee $P_{i}$ to firm $i$ and travels $m_{i}$ miles is then $2 \sqrt{\alpha_{t} m_{i}}-m_{i}-\tau\left|x-x_{i}\right|-P_{i}$.

A remark on the Hotelling specification is instructive at this stage. The Hotelling feature is used as a device to describe imperfect competition in a fully-covered market, as it is typically done in many IO models. We assume some degree of horizontal product differentiation, where the fictitious "transport" cost $\tau$ regulates the intensity of price competition. This parameter is not to be confused with miles travelled. ${ }^{11}$ What is relevant for our purposes is the presence of some "stickiness" in the market: once an insurance company slightly undercuts its rival, it will attract some of the rival's customers but not all of them. Similar results could have been obtained in a model with switching costs, or in a model of consumer search costs. ${ }^{12}$

\section{Discrimination over immutable variables}

We imagine first that companies sell their policies at a fixed price that does not depend on miles. This may be due to the fact that there does not exist a cheap technology that allows a firm to monitor the number of miles travelled by a customer or a technology that allows to charge a variable price. ${ }^{13}$ Since the marginal price per mile travelled is zero, a type $t$ would travel a number of miles $m_{t}=\alpha_{t}$, enjoying a gross surplus $V_{t}=\alpha_{t}$ from travelling, independently from the company it buys the policy from. What matters for the subscription choice is only the price differential and the "transport" cost. While it is impossible to charge different prices according to the number of miles travelled (i.e. a "mutable" variable that is directly correlated to the risk incurred by a person), a firm can obtain, at a negligible cost, the information about sex, an "immutable" variable that is only statistically but not causally correlated to risk. ${ }^{14}$

Firms care about the cost of each customer they insure. If a firm does discriminate according to sex, it incurs a unit cost $C_{m}=\theta\left[y \alpha_{h}+(1-y) \alpha_{l}\right]$ and $C_{w}=\theta\left[y \alpha_{l}+(1-\right.$ y) $\left.\alpha_{h}\right]<C_{m}$ for men and women respectively. On the other hand, if it does not discriminate the unit cost per subscriber is $\bar{C}=w C_{w}+(1-w) C_{m}=\theta\left[\alpha_{l}+s_{h}\left(\alpha_{h}-\alpha_{l}\right)\right]$. In the remainder we will assume:

$$
\alpha_{l}>3 \tau / 2+C_{m} .
$$

Assumption (A) is needed in order for every customer to prefer insuring against not insuring at all, so that the market will always be covered in equilibrium. ${ }^{15}$ Also notice that assumption (A) necessarily implies $\theta<1$, i.e. the model should have economic relevance (a customer that travels $\alpha$ miles enjoys a gross surplus of $\alpha$ and causes total costs equal to $\theta \alpha)$.

We are now in a position to analyse a two-stage game where firms decide first whether or not to discriminate according to gender, and then compete in prices. 
In the last stage, if both firms follow symmetric pricing policies (i.e. either they both discriminate or they both do not discriminate), we have a standard Hotelling game where the equilibrium prices offered to a customer group are equal to the cost created by that customer group plus the "transport" parameter. Equilibrium profits reflect only the locational advantage of a firm and do not depend on the ability to discriminate. In particular, when both firms do not discriminate, we have at equilibrium:

$$
\begin{aligned}
& P^{n, n}=\tau+\bar{C} \\
& \pi^{n, n}=\tau / 2
\end{aligned}
$$

where the superscript " $n, n$ " stands for the no-discrimination case for both firms. Assumption (A) ensures that all customers will buy the insurance policy since $\bar{C}<C_{m}$. Notice that "fair" prices for type $t=\{h, l\}$ would be $P^{f, t}=\theta \alpha_{t}$. Hence equilibrium prices differ from fair ones for two reasons, one due to imperfect competition ("transport" costs) and one that depends on the cross subsidy between high and low types. In particular, the unit subsidy $q_{t}$ given to type $t$ is:

$$
\begin{aligned}
q_{l} & =P^{f, l}-P^{n, n}=-\tau-s_{h} \theta\left(\alpha_{h}-\alpha_{l}\right) \\
q_{h} & =P^{f, h}-P^{n, n}=-\tau+s_{l} \theta\left(\alpha_{h}-\alpha_{l}\right)
\end{aligned}
$$

Low types "lose" from risk-specific fair prices both because competition is imperfect and because they subsidise high types that, on the other hand, "lose" from imperfect competition but "win" from the cross subsidy.

Similarly, if both firms discriminate according to class (sex) $c=\{$ man, woman $\}$, the equilibrium prices $P_{i w}$ and $P_{i m}$ they charge to women and men respectively and the corresponding profits are:

$$
\begin{aligned}
& P_{c}^{d, d}=\tau+C_{c} \\
& \pi^{d, d}=\tau / 2
\end{aligned}
$$

where " $d, d$ " means that both firms are discriminating according to class $c$. As before, profits are only dictated by Hotelling "transport" costs, while accident costs are fully passed on to customers, so that equilibrium profits are not affected compared to the " $n, n$ " case. ${ }^{16}$ Also notice that the "average" price charged by each firm coincides with the uniform price charged under no discrimination: $\bar{P}^{d, d}=w P_{w}^{d, d}+(1-w) P_{m}^{d, d}=\tau+\bar{C}$.

Since the classification used (sex) is imperfect, a type $t$ is still not charged fair prices on average (for instance a low type pays $P_{l}^{d, d}=\left[w y P_{w}^{d, d}+(1-w)(1-y) P_{m}^{d, d}\right] / s_{l}$ ), and subsidies are in this case:

$$
\begin{aligned}
q_{l} & =P^{f, l}-P_{l}^{d, d}=-\tau-\theta\left(\alpha_{h}-\alpha_{l}\right) y(1-y) / s_{l} \\
q_{h} & =P^{f, h}-P_{h}^{d, d}=-\tau+\theta\left(\alpha_{h}-\alpha_{l}\right) y(1-y) / s_{h}
\end{aligned}
$$

Compared to Eq. (2) it can be seen that the variance of the subsidies is now diminished. ${ }^{17}$ This will have implications when we discuss welfare properties in Section 3.1. 
In the asymmetric case " $d, n$ " where one firm discriminates and the rival charges a uniform price it is relatively straightforward to prove the following ${ }^{18}$ :

Proposition 1: Firms have a unilateral incentive to introduce discrimination over immutable variables.

To summarise our results, we have shown that there is a natural tendency for firms to introduce discrimination when the classification variable (sex) is not causally but only statistically and imperfectly correlated to the risk of a person since it is possible to get better cost information on average. This is in line with the casual evidence described in the Introduction. Discrimination over sex would also be introduced in the presence of small costs incurred to collect or process the information over the class (sex) to which the insured person belongs. In such a case firms are caught in a prisoner's dilemma, since overall they do not benefit from discrimination but would have to pay the associated (small) costs. Finally, notice that gender classification would also be introduced by a monopolist, although for different reasons: while imperfectly competitive firms adopt it because of the different costs of serving different observable classes, a monopoly firm would introduce it as a way to appropriate more consumer gross surplus that is higher for men than for women. ${ }^{19}$

These results are quite standard and in line with a conventional view on price discrimination. What is sometimes neglected is that discrimination also has redistributive effects since it reduces cross subsidies from low to high types. What we highlight next is the fact that such cross subsidies include a misclassification component that has welfare implications.

\subsection{Horizontal and vertical equity}

In the absence of some regulatory intervention, discrimination over an imperfect immutable variable such as sex would be introduced by firms. In the context just analysed, this would have no impact on efficiency when information collection costs are zero. Still, strategic interaction implies that pricing structures would be different with and without discrimination, hence it is important to study their effect on equity. In order to tackle this delicate question we adopt the framework of Schmalensee [1984], which is well suited to analyse the equity properties of a certain schedule of prices, for a given underlying cost structure.

Imagine in a population there is a distribution of various types $t$ with frequency $p(t)$, with actual costs $C_{t}$ per type. Imagine also there is some publicly available information that allows to classify the types into a certain number of classes $c$. This information gives the probability $p(c \mid t)$ that a type $t$ is classified into class $c$, and such information is imperfect, i.e. $0<p(c \mid t)<1$. Finally, let $P_{c}$ be the price that is charged to a person allocated to class $c$, while $P_{t}$ is the price charged on average to type $t$. Schmalensee defines an inequity function $I$ that depends on the schedule of prices and costs and demonstrates how, starting with reasonable axioms, $I$ could be expressed by the following functional form ${ }^{20}$ :

$$
I=\sum_{t} p(t)\left[\sum_{c} p(c \mid t)\left(P_{c}-C_{t}\right)^{2}\right]
$$


This function is zero when all prices are fair (i.e. each type pays only his/her actual cost $C_{t}$ ), while it increases when prices charged to a true type $t$ allocated to class $c$ deviate from the underlying costs, weighted by the frequency of type $t$. Schmalensee decomposes the overall equity function into two components, corresponding to two different types of inequity. On the one hand, inequity can derive from the presence of cross subsidies among types. This is defined "vertical" inequity and it is given by:

$$
V=\sum_{t} p(t)\left(P_{t}-C_{t}\right)^{2} .
$$

On the other hand, inequity can also arise since identical types may be treated differently if allocated to different classes. This is "horizontal" inequity:

$$
H=\sum_{t} p(t)\left[\sum_{c} p(c \mid t)\left(P_{c}-P_{t}\right)^{2}\right] .
$$

It is easy to show that $I=V+H$. It is immediate to apply this framework to our analysis, where we have two types $t=\{h, l\}$ and two classes $c=\{$ women, men $\}$. From Eqs. (1) and (3), and denoting $\Delta=\theta\left(\alpha_{h}-\alpha_{l}\right)$, we obtain ${ }^{21}$ :

$$
\begin{aligned}
H^{n} & =0 \\
I^{n} & =V^{n}=\tau^{2}+\Delta^{2} / 4
\end{aligned}
$$

when firms do not discriminate and

$$
\begin{aligned}
I^{d} & =\tau^{2}+y(1-y) \Delta^{2} \\
H^{d} & =y(1-y)(1-2 y)^{2} \Delta^{2} \\
V^{d} & =\tau^{2}+4 y^{2}(1-y)^{2} \Delta^{2}
\end{aligned}
$$

when firms do discriminate. Figure 2 illustrates the equity comparisons between discrimination and non discrimination.

The message that emerges is quite intuitive. If allowed, discrimination over gender (an immutable variable) would reduce overall inequity, since the variance of prices is reduced. This derives from two effects that do not necessarily go the same way. Cross subsidies between types decrease; however discrimination also introduces phenomena of misclassification, causing the appearance of horizontal inequity that would be absent if discrimination is not allowed. This latter type of inequity is zero only when $y=1 / 2$, i.e., when the classification available does not provide information and discrimination does not take place, or when $y=1$, i.e., when information is perfect. While the decrease in vertical inequity associated to price discrimination is arguably desirable (if we abstract from externalities or concerns that are outside the scope of this model), ${ }^{22}$ the downside of price discrimination is that it introduces a different type of cross-subsidy that affects customers in a random fashion. 


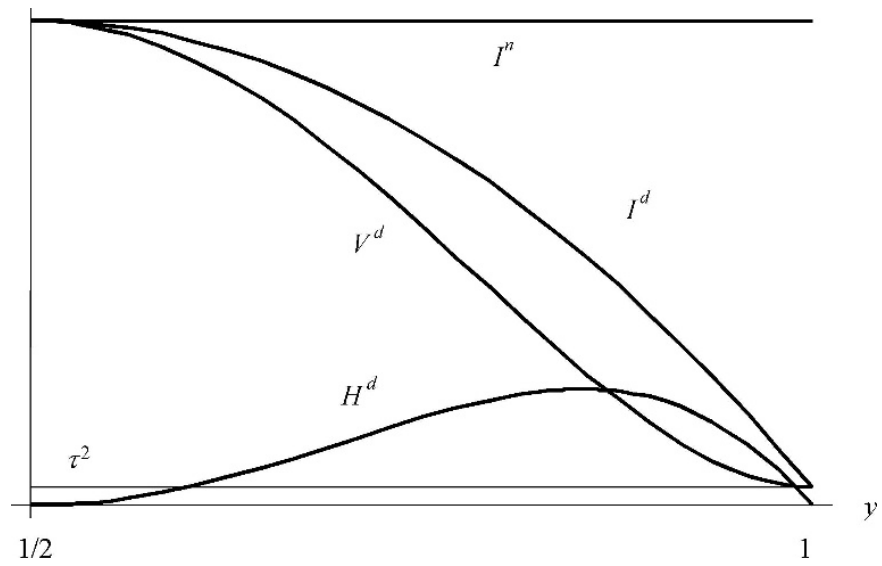

Figure 2. Horizontal and vertical inequity.

As shown by Hoy and Lambert [2000], the result on the decrease of vertical inequity is a general one that extends beyond the quadratic specification that we have used as long as individuals purchase the same amount of insurance, regardless of the pricing regime. It is also a general result that horizontal inequity is zero at $y=1 / 2$ and $y=1$, with a maximum in between. On the contrary, it cannot be stated in general that total inequity decreases everywhere with $y>1 / 2$. In fact, if the weight attributed to missclassification is big enough, it is possible to find cases where total inequity increases with $y$ at first, and then decreases. However, it should be clear that if $y$ is "high" enough, then all measures of inequity should decrease with $y$ (a sufficient but not necessary condition is that $y$ lies to the right of the peak reached by horizontal inequity).

The normative analysis in the context of the model that we have discussed so far can be conducted only in terms of equity, since efficiency is not affected by the ability to discriminate. This is due to the fact that customers' actions (i.e. miles travelled) are unaffected by the classification scheme. In the next section we analyse what happens when discrimination can have an impact on customers' actions besides the subscription decision.

\section{Discrimination over mutable variables}

\subsection{Non-linear prices}

In the previous section we assumed that companies could only charge fixed prices (i.e. mile independent), eventually discriminating according to the observable and immutable variable represented by the sex of the insured person. Even if the customer's type is not observed, a company knows that there is a distribution of different types that are willing to purchase different quantities (i.e. travel different amount of miles) so a firm could try to design different contracts for different types, relying on customers' self-selection. These contracts would be possible as long as there exists a monitoring technology that allows an insurer to monitor the number of miles travelled by the insured customer. Crocker and Snow 
(2000) refer to this practice as "categorization based on consumption choice". An example is the "black box" computer technology mentioned in the Introduction. In this section we imagine that such monitoring technologies exist at a negligible cost.

Assume first that gender discrimination is not allowed (as it is the case in many States in the US). Since there are only two types, the most general non-linear contracts that firm 1 could offer are represented by a pair of contracts that specify the number of miles that could be travelled and the corresponding price, one contract for each type: $\left\{m_{h 1}, P_{h 1}\right\}$, $\left\{m_{l 1}, P_{l 1}\right\}$. Firm 2 would design similar contracts. Market shares are then determined by the indifference condition for type $t=h, l$ :

$$
x_{t}=\frac{1}{2}+\frac{2 \sqrt{\alpha_{t} m_{t 1}}-m_{t 1}-P_{t 1}-\left(2 \sqrt{\alpha_{t} m_{t 2}}-m_{t 2}-P_{t 2}\right)}{2 \tau} .
$$

The problem that firm 1 has to solve is the following:

$$
\begin{aligned}
& \max _{\left\{m_{h 1}, p_{h 1}\right\},\left\{m_{l 1}, p_{l 1}\right\}} s_{h} x_{h}\left(P_{h 1}-\theta m_{h 1}\right)+s_{l} x_{l}\left(P_{l 1}-\theta m_{l 1}\right) \\
& \text { s.t. } \\
& I R_{l}: 2 \sqrt{\alpha_{l} m_{l 1}}-m_{l 1}-P_{l 1}-\tau x \geq 0, x \leq x_{l} \\
& I R_{h}: 2 \sqrt{\alpha_{h} m_{h 1}}-m_{h 1}-P_{h 1}-\tau x \geq 0, x \leq x_{h} \\
& I C_{l}: 2 \sqrt{\alpha_{l} m_{l 1}}-m_{l 1}-P_{l 1} \geq 2 \sqrt{\alpha_{l} m_{h 1}}-m_{h 1}-P_{h 1} \\
& I C_{h}: 2 \sqrt{\alpha_{h} m_{h 1}}-m_{h 1}-P_{h 1} \geq 2 \sqrt{\alpha_{h} m_{l 1}}-m_{l 1}-P_{l 1}
\end{aligned}
$$

While the previous programme may look quite complicated, since in principle there may be various binding combinations of the individual rationality (IR) and of the incentive compatibility (IC) constraints, the result is in fact very simple:

Proposition 2: $\quad$ When companies are able to offer non-linear contracts over the mutable variable (miles), full efficiency is obtained even if customer types are not directly observed.

Proof. Let us first assume that none of the constraints bind. Then there is no link between the contracts offered to high- and to low-types. Concentrating on a generic $t$-type, the FOC w.r.t. price gives (for notational simplicity we drop the subscripts that refer to firm 1):

$$
x_{t}+\left(P_{t}-\theta m_{t}\right) \frac{\partial x_{t}}{\partial P_{t}}=x_{t}-\left(P_{t}-\theta m_{t}\right) \frac{1}{2 \tau}=0
$$

At a symmetric equilibrium $x_{t}=1 / 2$, obtaining $P_{t}=\tau+\theta m_{t}$. From the FOC w.r.t. miles we get:

$$
\begin{aligned}
-\theta x_{t}+\left(P_{t}-\theta m_{t}\right) \frac{\partial x_{t}}{\partial m_{t}} & =-\theta x_{t}+\left(P_{t}-\theta m_{t}\right)\left(\sqrt{\alpha_{t} / m_{t}}-1\right) \frac{1}{2 \tau} \\
& =-\frac{\theta}{2}+\frac{\tau}{2 \tau}\left(\sqrt{\alpha_{t} / m_{t}}-1\right)=0
\end{aligned}
$$

These results then allow to obtain optimal contracts: $\left\{m_{l}=\alpha_{l} /(1+\theta)^{2}, P_{l}=\tau+\theta \alpha_{l} /(1+\right.$ $\left.\theta)^{2}\right\},\left\{m_{h}=\alpha_{h} /(1+\theta)^{2}, P_{h}=\tau+\theta \alpha_{h} /(1+\theta)^{2}\right\}$. Miles for each type are set at the socially efficient level. To confirm that the solutions we have found do represent an equilibrium, 
we still have to check the various constraints (we check only the more stringent IR for indifferent types located at $1 / 2$ :

$$
\begin{aligned}
I R_{l} & : \alpha_{l} /(1+\theta)-\tau-\tau / 2 \geq 0 \\
I R_{h} & : \alpha_{h} /(1+\theta)-\tau-\tau / 2 \geq 0 \\
I C_{l} & : \alpha_{l} /(1+\theta)-\tau \geq 2 \sqrt{\alpha_{l} \alpha_{h}} /(1+\theta)-\alpha_{h} /(1+\theta)-\tau \\
I C_{h} & : \alpha_{h} /(1+\theta)-\tau \geq 2 \sqrt{\alpha_{l} \alpha_{h}} /(1+\theta)-\alpha_{l} /(1+\theta)-\tau
\end{aligned}
$$

Since $\left(\alpha_{h}+\alpha_{l}\right)>2 \sqrt{\alpha_{l} \alpha_{h}}$ the IC conditions are always satisfied. Also, our initial assumption (A) implies that $\alpha_{l}>3 \tau /[2(1-\theta)]$, which ensures that $\mathrm{IR}_{l}$ and a fortiori $\mathrm{IR}_{h}$ are also satisfied.

This result deserves some comments. Each customer is offered the efficient amount of miles and pays the relative fair cost plus a term that depends on "transport" cost, i.e. on the intensity of price competition. These types of contracts are very simple to implement since they correspond to a two-part tariff common to everybody, where the variable component is equal to the marginal cost $\theta$ - inducing each customer to choose freely the optimal amount of miles - while the fixed component is simply equal to the unit "transport" cost $\tau$. This result implies that there is no need of direct monitoring of consumption choices. For instance, it could be put in practice by selling insurance with gasoline [Pay-at-the-Pump; see Wenzel, 1995]. It is important to stress that the result we have obtained would not occur in a monopoly situation, where there would be two standard binding constraints $\operatorname{IR}_{l}$ and $\left.\mathrm{IC}_{h}\right)$ and typical inefficiency "at-the-bottom" would arise from discrimination used as a screening device. Moreover, recent literature on competitive price discrimination in multidimensional models of heterogeneity indicates that the no-distortion result depends upon symmetry and market coverage [Armstrong and Vickers, 2001; Rochet and Stole, 2003].

Sticking to the model analysed in this paper, an immediate outcome of the previous Proposition is that even if firms do not observe directly the type, the competitive process attains efficiency over the mutable variable. Types are separated and firms have no reason to use any other information at their disposal such as the sex of the customer that is imperfectly correlated to a type. In fact, firms gain nothing by offering different non-linear contracts to men and women. Even if they tried to further discriminate according to sex, the contracts they would offer would just depend on type and not on sex. Offers to men's high-types would coincide with the contract offered to women's high types, and similarly for low types. Profits are made by the insurance companies because of their locational advantage over the closer customers, but they have no competitive advantage in supplying quantities (in particular, they gain nothing from distorting quantities). Hence we can state without proof the following:

Corollary 1: In the presence of arbitrarily small classification costs, firms never discriminate over sex when they can offer non-linear contracts over miles, even if types are not directly observed.

Contrary to the results of Section 3, there is no further strategic role played by any additional information that is just statistically correlated to the cost of an insured person. 
Our results say that categorization will not emerge in an oligopoly when utility is additive and firms compete in fully non-linear contracts, because such contracts are already efficient (Proposition 2), hence any additional amount of imperfectly correlated information would be useless. ${ }^{23}$

Why then are efficient non-linear contracts of the type just described not observed in practice while, on the contrary, class (gender) discrimination is pervasive where allowed? These are two intertwined questions. Firstly, the simple equilibrium two-part pricing structure that we have derived depends on several assumptions, such as symmetry, coverage and the separability in the utility function between type and "transport" costs. If such assumptions do not hold, non-linear contracts would be more complicated and difficult to implement. Non-linear contracts could then be put in practice only if monitoring technologies exist (e.g. black boxes with GPS). Such technologies could be expensive to adopt while class discrimination is much cheaper to introduce, see Edlin [2003]. In other words, while there may be many reasons that are outside our model that may give a role to categorization, ${ }^{24}$ even under the assumptions of our model we believe it makes sense to analyze linear contracts. These are "simple" and implementable pricing structures that would still allow a firm to charge according to miles. As we show in the next section, linear contracts immediately reintroduce categorization as a plausible equilibrium phenomenon.

\subsection{Linear prices}

In Section 3 we discussed how in the extreme (but realistic) situation of fixed-price contracts, insurance companies have a unilateral incentive to introduce class discrimination over immutable characteristics. In this section we discuss linear pricing, whereas a firm couldfor instance - charge at the gasoline station. This pricing structure needs no monitoring at all. Still, this kind of pricing allows the firm to charge over the mutable variable (i.e. the variable that is causally related to risk). In this context, we ask again the following question: Would any additional information on the imperfect immutable variable (sex) have any role? 25

Imagine firms compete over simple linear contracts, i.e. they charge only a price per mile, eventually discriminating between men and women. As we have done in the previous sections, assume first that firms do not discriminate according to sex. Firm $i$ charges a single price $p_{i}$ per mile. A type- $t, t=\{h, l\}$, that buys from firm $i$ travels $m_{t i}=\alpha_{t} /\left(1+p_{i}\right)^{2}$ miles and enjoys a surplus $C S_{t i}=\alpha_{t} /\left(1+p_{i}\right)$ (gross of "transport" costs). Since customers enjoy different surplus from travelling when buying from the two firms, the indifference condition that determines market shares depends on types:

$$
x_{t}=\frac{1}{2}+\frac{\alpha_{t}}{2 \tau} \frac{p_{2}-p_{1}}{\left(1+p_{1}\right)\left(1+p_{2}\right)}
$$

Firms' profits are:

$$
\begin{aligned}
\pi_{1} & =\left(p_{1}-\theta\right)\left(s_{h} m_{h} x_{h}+s_{l} m_{l} x_{l}\right)=\left(p_{1}-\theta\right)\left(s_{h} \alpha_{h} x_{h}+s_{l} \alpha_{l} x_{l}\right) /\left(1+p_{1}\right)^{2} \\
\pi_{2} & =\left(p_{2}-\theta\right)\left[s_{h} m_{h}\left(1-x_{h}\right)+s_{l} m_{l}\left(1-x_{l}\right)\right] \\
& =\left(p_{2}-\theta\right)\left[s_{h} \alpha_{h}\left(1-x_{h}\right)+s_{l} \alpha_{l}\left(1-x_{l}\right)\right] /\left(1+p_{2}\right)^{2}
\end{aligned}
$$


Concentrating on firm 1, its FOC can be manipulated into the following expression:

$$
\begin{aligned}
& {\left[\alpha_{h} s_{h} x_{h}+\alpha_{l} s_{l} x_{l}+\left(p_{1}-\theta\right)\left(\alpha_{h} s_{h} \frac{\partial x_{h}}{\partial p_{1}}+\alpha_{l} s_{l} \frac{\partial x_{l}}{\partial p_{1}}\right)\right]} \\
& \quad \times\left(1+p_{1}\right)-2\left(p_{1}-\theta\right)\left(\alpha_{h} s_{h} x_{h}+\alpha_{l} s_{l} x_{l}\right)=\left(\alpha_{h} s_{h} x_{h}+\alpha_{l} s_{l} x_{l}\right)\left(1+2 \theta-p_{1}\right) \\
& \quad-\left(p_{1}-\theta\right)\left(s_{h} \alpha_{h}^{2}+s_{l} \alpha_{l}^{2}\right) /\left[2 \tau\left(1+p_{1}\right)\right]=0
\end{aligned}
$$

At a symmetric equilibrium market shares are equal to $1 / 2$ both for high and low types, hence Eq. (4) simplifies to:

$$
\left(\alpha_{h}+\frac{1-s_{h}}{s_{h}} \alpha_{l}\right)\left(1+2 \theta-p_{1}\right)-\left(p_{1}-\theta\right)\left(\alpha_{h}^{2}+\frac{1-s_{h}}{s_{h}} \alpha_{l}^{2}\right) /\left[\tau\left(1+p_{1}\right)\right]=0
$$

We now turn to the " $d, d$ " case. There are four "indifferent" types according to class $c$ and type $t$ :

$$
x_{c t}=\frac{1}{2}+\frac{\alpha_{t}}{2 \tau} \frac{p_{2 c}-p_{1 c}}{\left(1+p_{1 c}\right)\left(1+p_{2 c}\right)}
$$

The expression for the profit of firm 1 is:

$$
\begin{aligned}
\pi_{1}= & \left.w\left(p_{1 w}-\theta\right)\left[(1-y) \alpha_{h} x_{w h}+y \alpha_{l} x_{w l}\right)\right] /\left(1+p_{1 w}\right)^{2} \\
& \left.+(1-w)\left(p_{1 m}-\theta\right)\left[y \alpha_{h} x_{m h}+(1-y) \alpha_{l} x_{m l}\right)\right] /\left(1+p_{1 m}\right)^{2}
\end{aligned}
$$

and the two FOCs relative to firm 1 can be rewritten as:

$$
\begin{aligned}
& {\left[\alpha_{h}(1-y) x_{w h}+\alpha_{l} y x_{w l}\right]\left(1+2 \theta-p_{1 w}\right)} \\
& \quad-\left(p_{1 w}-\theta\right)\left[(1-y) \alpha_{h}^{2}+y \alpha_{l}^{2}\right] /\left[2 \tau\left(1+p_{1 w}\right)\right]=0 \\
& {\left[\alpha_{h} y x_{m h}+\alpha_{l}(1-y) x_{m l}\right]\left(1+2 \theta-p_{1 m}\right)} \\
& \quad-\left(p_{1 m}-\theta\right)\left[y \alpha_{h}^{2}+(1-y) \alpha_{l}^{2}\right] /\left[2 \tau\left(1+p_{1 m}\right)\right]=0
\end{aligned}
$$

At a symmetric equilibrium:

$$
\begin{aligned}
& \left(\alpha_{h}+\frac{y}{1-y} \alpha_{l}\right)\left(1+2 \theta-p_{1 w}\right) \\
& -\left(p_{1 w}-\theta\right)\left(\alpha_{h}^{2}+\frac{y}{1-y} \alpha_{l}^{2}\right) /\left[\tau\left(1+p_{1 w}\right)\right]=0 \\
& \left(\alpha_{h}+\frac{1-y}{y} \alpha_{l}\right)\left(1+2 \theta-p_{1 m}\right) \\
& -\left(p_{1 m}-\theta\right)\left(\alpha_{h}^{2}+\frac{1-y}{y} \alpha_{l}^{2}\right) /\left[\tau\left(1+p_{1 m}\right)\right]=0
\end{aligned}
$$

We can now state the following: 
Proposition 3: When both firms discriminate according to sex, they charge lower unit prices to men and higher unit prices to women compared to the no discrimination case. Unit profits under discrimination decrease for men and increase for women. Overall expenditure by each type decreases under discrimination for men and increases for women if unit costs are sufficiently low.

Proof. At a symmetric equilibrium FOCs (4) and (9) can be all written in the following form:

$$
F(p, \kappa)=\left(\alpha_{h}+\kappa \alpha_{l}\right)(1+2 \theta-p)-(p-\theta)\left(\alpha_{h}^{2}+\kappa \alpha_{l}^{2}\right) /[\tau(1+p)]=0
$$

where $\kappa$ is equal to $\kappa_{n}=\left(1-s_{h}\right) / s_{h}$ in the " $n, n$ " case and equal to $\kappa_{w}=y /(1-y)$ and $\kappa_{m}=(1-y) / y$ for women and men respectively in the " $d, d$ " case.

First, notice by inspection of FOCs that the equilibrium price lies in the interval $\theta<$ $p<2 \theta+1$. Second, the equilibrium surplus of an indifferent type is $\alpha_{t} /(1+p)-\tau / 2$ $>\alpha_{t} /[2(\theta+1)]-\tau / 2$ which is always positive given assumption (A) (i.e. the market is covered). Doing comparative statics at equilibrium, we have:

$$
\begin{aligned}
\frac{d p}{d \kappa}= & -\frac{\partial F(\cdot) / \partial \kappa}{\partial F(\cdot) / \partial p}=\alpha_{l}\left[1+2 \theta-p-\frac{p-\theta}{\tau(1+p)} \alpha_{l}\right] / \\
& \times\left[\alpha_{h}+\kappa \alpha_{l}+\frac{\left(\alpha_{h}^{2}+\kappa \alpha_{l}^{2}\right)(1+\theta)}{\tau(1+p)^{2}}\right] \\
& =\frac{\alpha_{h} \alpha_{l}\left(\alpha_{h}-\alpha_{l}\right)(1+2 \theta-p)}{\left(\alpha_{h}+\kappa \alpha_{l}\right)\left(\alpha_{h}^{2}+\kappa \alpha_{l}^{2}\right)} \frac{1}{1+\frac{(1+2 \theta-p)(1+\theta)}{(p-\theta)(1+p)}}>0
\end{aligned}
$$

The comparison between prices then depends on the relative magnitude of $\kappa$. It is immediate to get that there is price bracketing: if $y>s_{h}$ then prices are higher for men without discrimination while the opposite holds for women. Since the inequality $y>s_{h}=w+y-$ $2 w y$ is always satisfied when $y>1 / 2$, then $\kappa_{m}<\kappa_{n}<\kappa_{w}$ and men pay less per unit under discrimination.

A decrease in the unit price for men means they would be travelling more, hence a decrease in unit price may not necessarily imply a decrease of profits or total expenditure. However, the profit made by firms on a type $t$ is equal to $\alpha_{t}(p-\theta) /(1+p)^{2}$ which is strictly increasing in $p$ in the relevant interval. Hence it follows that under discrimination the profit made on each man would decrease, while it would increase for women. Also, the total amount spent by a type $t$ is $p m_{t}=\alpha_{t} p /(1+p)^{2}$, which is increasing in $p$ iff $p<1$. This is true only when $\theta$ is very small, in which case under discrimination men would also pay less overall, while women would pay more.

Notice that the price bracketing that we obtain here is the reverse of what happens when discrimination occurs with fixed fees (see Eqs. (1) and (3) in Section 3). When consumers decide where to get their insurance from, they take into account two components: the gross surplus they enjoy from consumption, and the location of the firms. Imagine we take two different types at the same location: as the gross surplus now increases with types, while the 
Hotelling dis-utility would be the same, it is clear that high-types are more responsive to price changes than low-types. This latter aspect arises only in the duopoly case. It is in fact worth noting that our model has the property that price discrimination would not be introduced by a monopoly firm under linear pricing. This is because the elasticity of subscribers in terms of miles travelled does not depend on type $t$ as $\varepsilon_{m t}=\frac{\partial m_{t}}{\partial p_{i}} \frac{p_{i}}{m_{t}}=-\frac{2 p_{i}}{\left(1+p_{i}\right)}$. A monopoly firm that applies the inverse elasticity rule would then offer the same price to every customer since the unit cost and the elasticities are the same. On the other hand, what matters for firms in a duopoly is the elasticity in terms of market shares, i.e. $\varepsilon_{x t}=\frac{\partial x_{t}}{\partial p_{i}} \frac{p_{i}}{x_{t}}=-\frac{\alpha_{t}}{2 t\left(1+p_{i}\right)^{2}} \frac{p_{i}}{x_{t}}$. At equilibrium, $x_{h}=x_{l}=1 / 2$, hence subscription demand of high types is more elastic than low types at a given price. Since men include more high types than low types, this explains the reverse price bracketing with lower unit prices charged to men at equilibrium. What matters for price discrimination in an oligopoly is the inter-firm price elasticity. On average, men travel more than women and this makes them particularly sensitive to changes in the price per-mile. This also helps understanding our next result. Contrary to the monopoly benchmark, imperfectly competitive firms would discriminate when they have the ability to do so:

Proposition 4: Price discrimination is a dominant strategy.

Proof. We have already shown by revealed preference that a firm prefers to discriminate over sex if the rival also discriminates. What remains to be done is to check that a firm is better off by discriminating also when the rival is not discriminating. Imagine firm 1 discriminates by offering two different prices to men and to women, while its rival does not discriminate. First, notice that the expression for the profit $\pi^{d, n}$ would be identical to Eq. (7), with the difference that expressions (6) for "indifferent" types would have a uniform $p_{2}$ rather than discriminatory $p_{2 h}$. This does not change the form of FOCs of the discriminatory firm that would still be given by Eq. (8), a part from $x_{c t}$ that would take different values. The value taken by FOCs starting from $p^{n}$ given by Eq. (5) are:

$$
\begin{aligned}
\left.\frac{\partial \pi^{d, n}}{\partial p_{m}}\right|_{p_{m}=p^{n}}= & \frac{1-y}{2}\left[\left(\alpha_{h}+\frac{y}{1-y} \alpha_{l}\right)\left(1+2 \theta-p^{n}\right)\right. \\
& \left.-\frac{p^{n}-\theta}{\tau\left(1+p^{n}\right)}\left(\alpha_{h}^{2}+\frac{y}{1-y} \alpha_{l}^{2}\right)\right] \\
= & \frac{1-y}{2} \frac{p^{n}-\theta}{\tau\left(1+p^{n}\right)} \frac{\alpha_{l} \alpha_{h}\left(\alpha_{h}-\alpha_{l}\right)}{\alpha_{h}+\kappa_{n} \alpha_{l}}\left(\kappa_{m}-\kappa_{n}\right)<0 \\
\left.\frac{\partial \pi^{d, n}}{\partial p_{w}}\right|_{p_{w}=p^{u}}= & \frac{y}{2}\left[\left(\alpha_{h}+\frac{1-y}{y} \alpha_{l}\right)\left(1+2 \theta-p^{n}\right)-\frac{p^{n}-\theta}{\tau\left(1+p^{n}\right)}\left(\alpha_{h}^{2}+\frac{1-y}{y} \alpha_{l}^{2}\right)\right] \\
= & \frac{y}{2} \frac{p^{n}-\theta}{\tau\left(1+p^{n}\right)} \frac{\alpha_{l} \alpha_{h}\left(\alpha_{h}-\alpha_{l}\right)}{\alpha_{h}+\kappa_{n} \alpha_{l}}\left(\kappa_{w}-\kappa_{n}\right)>0
\end{aligned}
$$

Hence, by starting with uniform prices when facing a rival that also charges uniform prices, a firm is better off by slightly increasing women's prices and decreasing men's prices. 
The strategic role of discrimination over sex to exploit different elasticities of different classes of customers is restored here, as in Section 3. But while in Section 3 it could be claimed that sex classification was caused by the fact that the company could identify different costs for different subgroups (gender classification did not alter customers' behaviour), here firms have the ability to charge according to miles, a "perfect" variable that is directly related to risk. It is then possible to argue that sex classification would still be of a fundamental strategic importance, despite not having any causal correlation to risk, at least until firms do not have the ability to implement non-linear pricing schedules of the kind discussed in Section 4.1. In this respect, a common claim that the adoption of new classification parameters is always caused by the attempt to reduce the asymmetry of information between an insured person and the insurance company does not seem to be well grounded. In this case, discrimination is introduced as a strategic device to exploit different elasticities with respect to market shares, while the unit cost caused by both types is the same.

To summarise, the model that we have analysed is constructed in a way such that a monopolist would not price discriminate over sex when it uses linear prices per mile. This is because the elasticity of miles is type-independent since the number of miles chosen by a given type is a fraction of that selected by the other type. Hence in this case price discrimination is introduced only for strategic reasons rather than for informational concerns. Firms have an incentive to price discriminate in order to exploit the fact that the degree to which customers switch from one firm to the other following a price change is type-dependent. High types evaluate the benefits from travelling miles more than low types, hence other factors such as the locational advantage of each firm have a lower weight in the insurance decision for higher types than for lower types. As a result, competition is tougher for men that consist of a disproportionate fraction of high types than for women that include more low types and local monopoly power can be exerted on them.

\subsection{Efficiency and equity considerations}

There are two sets of relevant comparisons that are interesting to make. First, we want to discuss how the ability to discriminate impacts on the various players under linear pricing. Secondly, we want to compare the properties of fixed policies as opposed to variable pricing policies, since the latter affect efficiency while the former do not.

We have shown in Proposition 4 that, under linear pricing, discrimination is a dominant strategy, as in Section 3. In Section 3 we also found that the equilibrium profit was always the same, with and without discrimination. This result does not hold anymore under linear pricing. To analyse the overall effect on profits we consider $\Delta \pi(w)=\pi^{d, d}(w)-\pi^{n, n}(w)$. First notice from Eqs. (5) and (9) that prices and profits are identical in the two limit cases when the population is made only of women or only of men, i.e. $\Delta \pi(0)=0, \Delta \pi(1)=$ 0 . Now we check if $\Delta \pi(w)$ is convex in $w$, in which case there would be a prisoner's dilemma. From Eq. (9), it is clear that equilibrium prices are not affected by $w$. Hence, applying the envelope theorem and using Eq. (5) that defined the equilibrium price $p^{n}$ under 
no-discrimination, we have at equilibrium:

$$
\begin{aligned}
& \frac{d \pi^{n, n}}{d w}=-(2 y-1)\left(\alpha_{h}-\alpha_{l}\right) \frac{p^{n}-\theta}{\left(1+p^{n}\right)^{2}}+\underbrace{\frac{\partial \pi_{i}}{\partial p_{j}} \frac{\partial p^{n}}{\partial w}}_{A(w)} \\
& \frac{d^{2} \Delta \pi}{d w^{2}}=-\frac{d^{2} \pi^{n, n}}{d w^{2}}=\underbrace{(2 y-1)\left(\alpha_{h}-\alpha_{l}\right) \frac{1+2 \theta-p^{n}}{(1+p)^{3}} \frac{\partial p^{n}}{\partial w}}_{+}+\underbrace{\frac{d A}{d w}}_{?}
\end{aligned}
$$

In general it is difficult to sign the second term in Eq. (11), while the first term is unambiguously positive since $\frac{\partial p^{n}}{\partial w}=\frac{\partial p^{n}}{\partial \kappa_{n}} \frac{\partial \kappa_{n}}{\partial s_{h}} \frac{\partial s_{h}}{\partial w}=\frac{2 y-1}{s_{h}^{2}} \frac{\partial p^{n}}{\partial \kappa_{n}}>0$ from Eq. (10). We conducted several simulations that show that the overall effect can go either way. The positive effect from the first term may be reinforced or reversed by the second term. Hence it is not necessarily the case that firms would be caught in a prisoner's dilemma by their ability to discriminate. Figure 3(a) gives an example where the ability to price discrimination yields higher profits for both firms.

In figure 3 we also draw horizontal and vertical equity, defined as in Section 3.1. Inequity measures are calculated in two different ways. ${ }^{26}$ In figure $3(\mathrm{~b})$ we base equity considerations on unit (i.e. per mile) prices and costs, while in figure 3(c) we consider total expenditure and costs. Both versions provide some interesting insights. In figure $3(\mathrm{~b})$, horizontal inequity is clearly zero when there is no price discrimination (there is no misclassification on "units" when the same price per mile is charged to everybody). When discrimination is allowed, horizontal inequity would emerge, in line with figure 2 . However, under discrimination, total inequity would increase compared to the no-discrimination case, contrary both to figure 2 and to some common perception about competitive discrimination. This is a direct implication of Proposition 3: with discrimination unit prices paid by men decrease, whilst those paid by women increase, cross-subsidies then increase in the "wrong" direction under discrimination, i.e. low types subsidise even further high types. In figure 3(c) we consider inequity based on total expenditure and costs, arguably a better measure since comparisons are made on the "true" costs caused by a certain type. There is a new feature that arises and that deserves some comments. Under linear pricing, there would be some degree of horizontal inequity even without discrimination, contrary to both the previous case and the case of no-discriminatory fixed prices. This is because horizontal inequity now has to do with the total price paid by a type compared with the average total price paid by all customers. With uniform linear pricing it is still the case that high types travel more and spend more than low types, which generates some level of horizontal inequity even in the non discrimination case. This also explains why the introduction of discrimination may cause a decrease in horizontal inequity. When $\theta$ is low, we know from Proposition 3 that men (made of relatively more high types) would spend less than under uniform pricing, and the opposite would occur for women. Hence there is a re-balancing of total prices between classes that decreases the level of horizontal inequity.

We should make two related remarks. First, notice from figure 3 how, in general, it is quite difficult to make unambiguous statements on equity properties of discrimination 


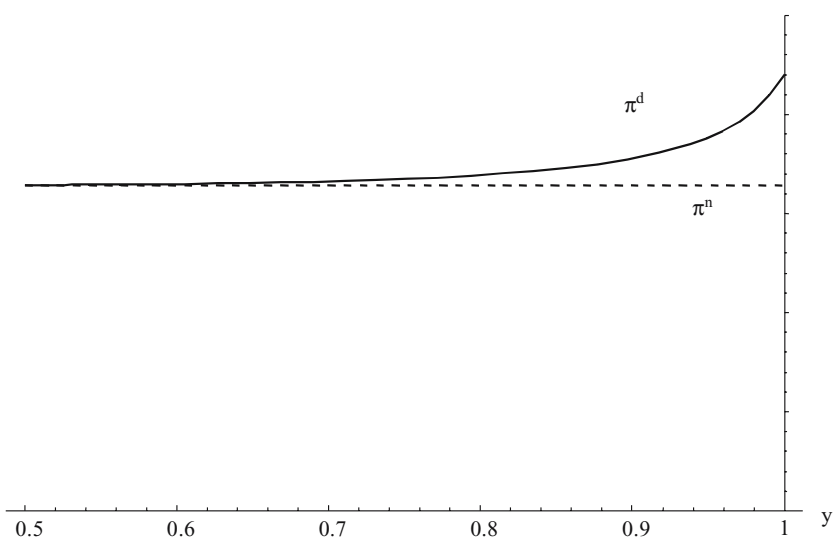

(a)

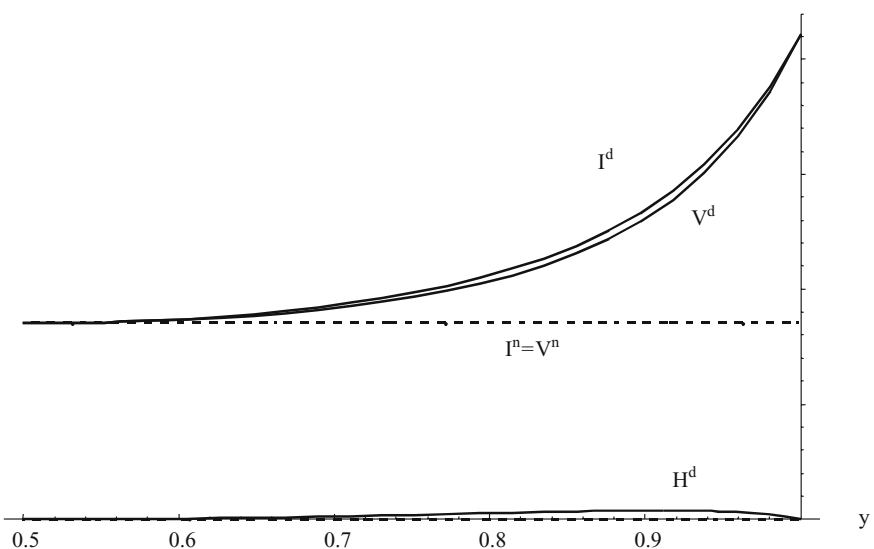

(b)

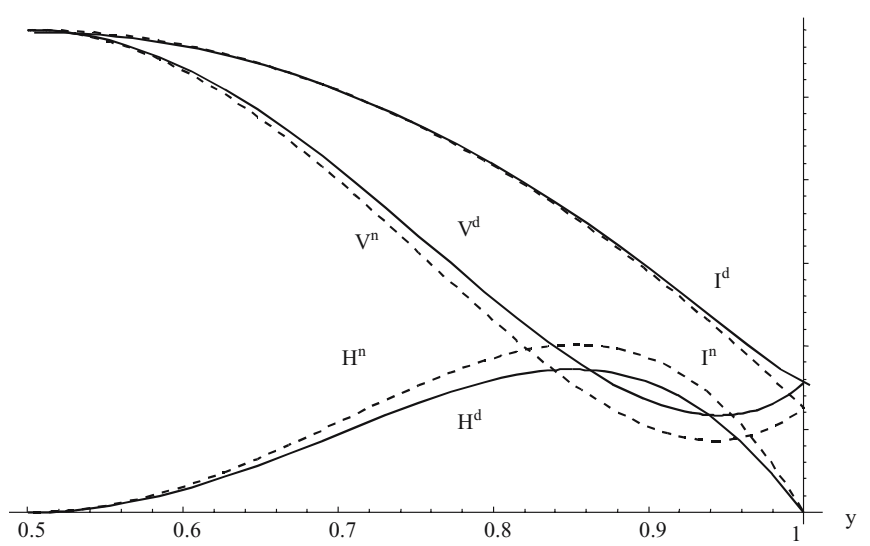

(c)

Figure 3. (a) Profits under linear pricing, (b) Per mile inequity under linear pricing $\left(\mathrm{H}^{n}=0\right.$ ), and (c) Inequity under linear pricing. 
versus non discrimination. Second, even the monotonic results of the impact of the accuracy of information on vertical inequity that we showed in Section 3.1 no longer hold here. This is in contrast with Theorem 2 of Hoy and Lambert [2000]. The reason for this discrepancy lies in the fact that they assume that individuals purchase constant amounts of insurance under both regimes, with and without price discrimination. While this assumption did hold in Section 3.1 (the amount of miles driven was invariant to the discrimination regime since the marginal price per mile was zero in either cases), here pricing affects consumption in the way we showed above.

When firms charge per mile travelled, the efficiency of the resulting allocation will be affected. In general, if we denote by $p$ the price per mile, then a customer would travel a number of miles equal to $m_{t}=\alpha_{t} /(1+p)^{2}$ and would enjoy a surplus $C S_{t}=\alpha_{t} /(1+p)$ (this surplus is gross of "transport" costs). Total surplus is $C S_{t}+(p-\theta) m_{t}=\alpha_{t}(1+2 p-\theta) /(1$ $+p)^{2}$ which is maximised when $p=\theta$. Since unit charges always include a mark-up over $\theta$ it then results that price discrimination increases efficiency when the fraction of women is relatively small. In this case, in fact, price discrimination improves the allocation for men (as their price gets closer to cost) and this effect prevails over the worsened allocation for women that are charged more than without discrimination, and hence travel less.

It is also interesting to make a comparison between fixed and linear prices. Compared to fixed pricing policies that induce "over-consumption" of miles, prices per mile induce "under-consumption" ( since $p>\theta$ ) but may have superior efficiency properties as long as $p<2 \theta /(1-\theta)$. From FOCs we know that in equilibrium both discriminatory and non-discriminatory prices lie in the range $\theta<p<(1+2 \theta)$; a sufficient condition for total surplus to be higher with per mile prices than with fixed prices is $\theta>1 / 2$. On the other hand, if $\theta$ is zero in the limit, for sure fixed pricing policies are superior since they induce no efficiency loss at all.

The last set of comparisons we make concerns the consumer point of view. In particular, we imagine that classification based on sex is banned by the regulator and we focus on consumer surplus CS (gross of "transport" costs) and inequity in the two remaining cases: we contrast the symmetric equilibrium with fixed pricing (superscript "f") with the symmetric equilibrium under variable pricing (superscript "v"). The average consumer surplus in the two cases is respectively:

$$
\begin{aligned}
C S^{f} & =\bar{\alpha}-t-\bar{c}=\bar{\alpha}(1-\theta)-\tau \\
C S^{v} & =\bar{\alpha} /\left(1+p^{v}\right)
\end{aligned}
$$

where $\bar{\alpha}=s_{h} \alpha_{h}+\left(1-s_{h}\right) \alpha_{l}$ and $p^{v}$ is the solution to Eq. (5). Since we know that $\theta$ $<p^{v}<1+2 \theta$, then it is easy to show that $C S^{v}>C S^{f}$ when $p^{v}$ is close to $\theta$. On the other hand, when $p^{v}$ is close to $1+2 \theta$, then a sufficient condition for a variable policy to be superior to a fixed policy from the consumer point of view is that $\theta>\sqrt{2} / 2$, or $\bar{\alpha}<2 \tau(1+\theta) /\left(1-2 \theta^{2}\right)$ when $\theta \leq \sqrt{2} / 2$. In figure $4,{ }^{27}$ it is also clear that variable pricing has "better" properties on average on equity grounds under our quadratic specification of inequity. From a normative point of view, it would then seem a good idea to introduce insurance policies based on consumption. 


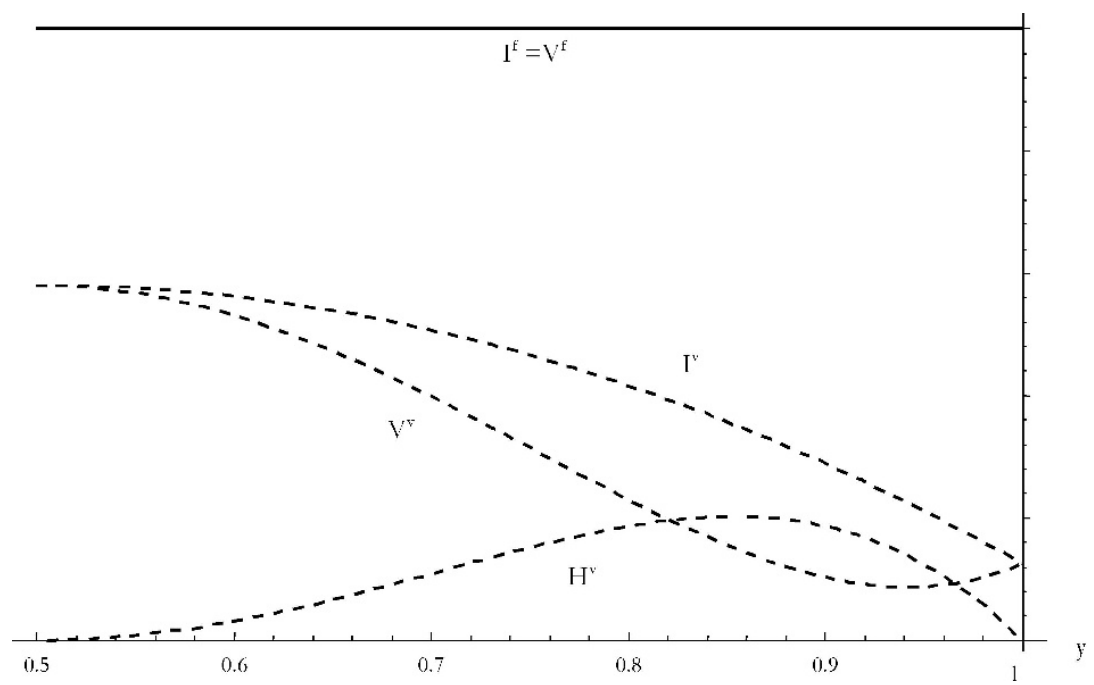

Figure 4. Inequity of fixed and variable insurance policies $\left(\mathrm{H}^{f}=0\right)$.

\section{Summary and conclusions}

This paper has analysed the problem of price discrimination in compulsory insurance markets such as car insurance. When competing firms do not observe a customer's type, but only some other variable correlated to it, we have argued that there is a strong incentive for firms to introduce classification based on immutable characteristics such as sex. This is not only due to more obvious information concerns, but also to more subtle strategic reasons. This is most evident when firms can-in principle-offer per-mile pricing, i.e. a pricing structure that targets the "true" underlying cost. Hence it is not true that if insurance companies adopted per-mile pricing they would not want to introduce discrimination based on sex. This type of classification (based on an immutable variable) has implications in terms of equity that are often neglected. In particular it would introduce misclassification ("horizontal" inequity). Only when some monitoring technology allows to charge fully non-linear prices, based on consumption choices, the strategic role played by any additional information contained in "imperfect" variables would be eliminated and contracts would be efficient in the context of our model.

Table 1 summarises our results. The baseline case in which insurers are not permitted to charge mileage-based premiums obtains standard results in line with conventional wisdom: firms get better cost information on average, hence they are willing to adopt gender classification, charging more for men (that contain more high-cost types) than for women. However profits are dissipated by competition among firms that, in equilibrium, are no better off than without discrimination. In fact, if classification is slightly costly, they are caught in a prisoner's dilemma. As classification does not concern consumption, efficiency is not affected, unless there are such classification costs. Cross-subsidies between types are 
Table 1. Summary of main results.

\begin{tabular}{|c|c|c|c|c|c|c|}
\hline $\begin{array}{l}\text { Discrimination } \\
\text { over: }\end{array}$ & $\begin{array}{l}\text { Price discrimin. } \\
\text { introduced? }\end{array}$ & $\begin{array}{l}\text { Impact on } \\
\text { prices }\end{array}$ & $\begin{array}{l}\text { Impact on } \\
\text { profits }\end{array}$ & $\begin{array}{l}\text { Impact on } \\
\text { CS }\end{array}$ & $\begin{array}{l}\text { Impact on } \\
\text { efficiency }\end{array}$ & $\begin{array}{l}\text { Impact on } \\
\text { equity }\end{array}$ \\
\hline $\begin{array}{l}\text { Immutable } \\
\text { variables }\end{array}$ & $\begin{array}{c}\text { (Monopoly: yes) } \\
\text { Duopoly: yes }\end{array}$ & $\begin{array}{l}\mathrm{M}:+ \\
\mathrm{W}:-\end{array}$ & $\begin{array}{c}\text { Neutral } \\
\text { (prisoner's } \\
\text { dilemma) }\end{array}$ & $\begin{array}{l}\mathrm{M}:- \\
\mathrm{W}:+\end{array}$ & $\begin{array}{l}\text { No change } \\
\text { (inefficient) }\end{array}$ & $\begin{array}{l}\text { H: introduced } \\
\text { V: decreased } \\
\text { I: decreased }\end{array}$ \\
\hline $\begin{array}{l}\text { Mutable variables: } \\
\text { non-linear prices }\end{array}$ & $\begin{array}{c}\text { (Monopoly: yes) } \\
\text { Duopoly: no }\end{array}$ & $\begin{array}{l}\text { Two-part } \\
\text { tariffs }\end{array}$ & - & - & $\begin{array}{c}\text { First best } \\
\text { (separability) }\end{array}$ & - \\
\hline $\begin{array}{l}\text { Mutable variables: } \\
\text { linear prices }\end{array}$ & $\begin{array}{c}\text { (Monopoly: no) } \\
\text { Duopoly: yes }\end{array}$ & $\begin{array}{l}\mathrm{M}:- \\
\mathrm{W}:+\end{array}$ & Ambiguous & $\begin{array}{l}\mathrm{M}:+ \\
\mathrm{W}:-\end{array}$ & $\begin{array}{c}\text { Increased if } w \\
\text { small }\end{array}$ & See figure 3 \\
\hline
\end{tabular}

reduced, hence vertical inequity is reduced, although discrimination introduces cases of horizontal misclassification. Under the specification of inequity proposed by Schmalensee [1984], total inequity decreases overall.

In contrast, when insurers are able to craft non-linear contracts that use observed miles and premiums to sort consumers, first-best contracts are achieved, so that private information engenders no efficiency costs, and gender discrimination is irrelevant. Competition, albeit imperfect, wipes away the screening ability typical of a monopolist that would discriminate between genders since they contain different proportions of high- and low-types. This contrast between monopoly and duopoly depends on the separability in the utility function between types and inter-firm elasticity (described by the Hotelling "transport" cost).

The more interesting — and arguably realistic_case concerns the last set of results. While gender-discrimination is once again a dominant strategy by the insurers, this arises purely for strategic reasons and it entails charging the high-cost gender a lower premium than the lower-cost gender. We constructed our model with the intent of generating such opposing results. We have used a very simple functional form, however the flavour of our main results can be generalised. A monopolist would not discriminate between types as long as their mile elasticities are the same. This can be obtained more in general with indirect utility functions where the customer's type enters multiplicatively. In the duopoly case, inter-firm elasticity plays a role that is absent in the monopoly case. To the extent that high types enjoy a higher surplus at a given price than low types, then the high-risk gender will be on average more price responsive to a price change and men will be charged lower unit premiums than women in equilibrium.

From the normative point of view, our results could be used to clarify some ambiguities and misperceptions that are present in the current regulatory debate. In particular, risk classification is seen in a rather contrasting way in the US and in the EU. In the EU one of the fundamental principles is "freedom of contract" for private firms - stated for the first time in an explicit way in the Third Non-life Insurance Directive (92/49/EEC) — that should be rejected only when it creates injustice. In insurance markets injustice means a violation of privacy and an unequal treatment among citizens. A discriminatory treatment of insured 
customers is generally accepted when it is motivated by legitimated purposes and based on "objective" criteria (such as the "bonus-malus" system; Schoorens, [1999]). Since allocative efficiency is a legitimate objective, it is rare that firms' "freedom of contract" is challenged. To illustrate this, the Commission has accused some member countries (Belgium, Finland, France and Luxembourg) of infringing this principle by imposing insurance companies to adopt the same national scheme of the bonus-malus system. The Commission said it would challenge any system that has automatic and mandatory repercussions on premiums in breach of the principle of tariff freedom. ${ }^{28}$

Federal rules exist in the US, based on a ban of "unfair discrimination", i.e. price differences that are not driven by a difference in costs. However, this principle has received interpretations different from the EU. Firstly, companies need to show that the classification variable has explicative power (in actuarial terms). Starting in the 70s, variables such as age, sex, marital status, race and religion have been opposed, not just on ethical reasons, but because of their "immutable" nature. More recently, territorial rating has also been challenged in many States ${ }^{29}$ because it is often a proxy for race, and because it has been recognised-in car insurance - that those that live in urban areas have to bear the negative externality due to congestion. Some States severely limit the type of classification variables that can be used. In California, for example, car insurance companies must adopt three types of classification (driving experience, miles driven in a year, and driving safety record). In addition, they may adopt some other variables contained in a list, but only if they can prove their explanatory power. It is then possible to argue that in the US, particularly in markets subject to compulsory insurance, cross-subsidies are tolerated, especially when they are related to immutable variables.

We have argued that the properties of pricing policies that are not yet fully non-linear, but are nevertheless based on consumption, are quite good. Examples of these policies that have recently started to emerge thanks to technological advances could be pay-as-you-drive, per-mile pricing, pay-at-the-pump, etc. Our results also corroborate the idea that variable charges have a beneficial impact on welfare, especially when firms learn how to use them implementing non-linear pricing. Since the devices that are needed could also be employed in alternative uses, our arguments may be used to support their adoption. ${ }^{30}$

\section{Acknowledgment}

We thank Silvia Sonderegger and Stefan Szymanski for helpful comments. We are especially indebted to the Editor and to an anonymous referee who gave us very detailed comments that have improved our paper greatly. Remaining errors are ours.

\section{Notes}

1. This positive effect (reduction of adverse selection) is mitigated when classification produces new and irreversible information (e.g. a genetic test) that may jeopardise the ability of a customer to get insurance [Hoy, 1989]. Rea [1992] also shows that, when the introduction of classification parameters is costly, competitive markets tend to result in "excessive" classification.

2. Concentration indices for the top 5 insurance companies in the Non-Life business in Europe ranged in 2002 from a minimum of $27 \%$ in Germany to a high $89 \%$ in Finland. 
3. The term "price discrimination" may generate some confusion. Stole (2001, based on Stigler) writes that "a firm price discriminates when the ratio in prices is different from the ratio in marginal costs for two similar (possibly identical) goods offered by the firm". In our model, when firms offer fixed-price policies, the cost of different types would differ, hence discrimination would be present when prices are uniform. On the other hand - since per-mile costs of different types are identical - when firms offer linear (per mile) prices, discrimination would occur when different prices are charged to different classes. To avoid this confusion (that has to do with the notion of "marginal" unit), in our paper by price discrimination we mean different prices charged to different classes of customers. In other words, price discrimination and classification based on gender are synonymous.

4. The black box device is installed in customers' cars and collects data about car usage on an ongoing basis. The company could monitor the data either via checking the black box or by adopting a technology similar to that used in mobile phones (GPS satellites track vehicles via electronic black boxes fixed to car dashboards).

5. Norwich Union launched in 2002 a PAYD pilot scheme in the UK, aimed at personalising motor insurance payments by using "black box" computer technology. Norwich Union has an exclusive agreement with US insurer, Progressive, to operate the scheme. The project is piloted among 5,000 people, before an expected roll out in 2005 across the UK and Europe (http://www.norwichunion.co.uk/pay_as_you_drive/). The French insurer AXA launched a similar scheme in Italy in September 2002. On the technical pros and cons of various PAYD schemes, see Litman [2001], Khazzoom [2000] and Kavalec and Woods [1999].

6. In 2000 , the size of the market for compulsory insurance coverage for auto liability amounted to $€ 51,1$ billion in the European Union (equivalent to $€ 242$ per vehicle per annum). This corresponded to roughly $9 \%$ of the insurance industry overall ( $21 \%$ of the non-life segment). Compulsory insurance is not limited to auto liability, e.g. it is a mandatory requirement for permission to run a business, transport goods, employ personnel.

7. This may be due to several reasons, the most important one being the very nature of third-party contracts. If somebody causes an accident, the insurer would have to reimburse the loss to the third-party and then claim the deductible back from its insured customer, which is a costly activity. As a result, all companies seem to disincentivize this using their prices.

8. Price differences refer to the average price differences between male and female customers, calculated for a sample of 25 firms (comprising the top 20 companies in 1999, accounting for more than $90 \%$ of the market). Prices are weighted by characteristics such as age or residence, hence the plot reflects only gender differences.

9. To illustrate this, we have come across an amusing recent case. Suncorp Metway, an Australian insurance company in Queensland, conducted a study in 2002 based on the number of car accident claims it received over the previous three years (http://corporate.suncorpmetway.com.au/news/news0142.asp). It found that those born under the star sign Gemini were the state's worst drivers. They were closely followed by Taurean drivers, while those with the star sign Capricorn had the least car accident claims. We are not entirely sure if the statement of Suncorp Metway national manager, Warren Duke, is sufficiently safe: "We always look for trends in claims to see if there are ways to reduce our pricing, but there is no intention to introduce astrology as a rating factor for motor insurance," he said.

10. We have solved a more general version of the model with the fraction of $h$-types not correlated between genders, while still preserving that men are riskier on average, $0 \leq y_{w}<y_{m} \leq 1$. The nature of our results is not affected. The main advantage of our assumption $y_{m}=y=1-y_{w}$ is that $y$ becomes a good indicator the accuracy of information and allows for simple two-dimensional diagrams.

11. To be sure, "miles travelled" and "transport" costs are two different things in our model. The former refers to a consumption good for the consumers, the marginal utility of which depends on the consumer type, while the latter refers to horizontal differentiation.

12. The Hotelling specification may also capture in a more direct way a specific feature of the insurance industry when the distribution and geographical location of branches is important. In Italy for example, telephony or Internet insurance represents only between 2 and 3\% of total premiums collected. In such a context, the location of branches plays a major role in the customer decision where to buy their policy (e.g. a customer would not travel many miles away from her home/working place to buy a policy that allows to save only a few euros).

13. For instance, it is unfeasible for a firm to strike a deal with a petrol station, selling insurance with gasoline (the Pay-at-the-Pump system, surveyed in its variants by Wenzel [1995]). In Section 4.1 we relax this assumption. 
14. The terminology is taken from Crocker and Snow [2000] while Hoy [1982] talks about 'unalterable' variables.

15. Assumption (A) ensures "full coverage" since it says that, in equilibrium, even a low-type that belongs to the class "man" and has the highest transportation costs (his/her location is the middle of the market) would buy a policy. This customer has a gross benefit of $\alpha_{l}$, and-as we show below-under price discrimination pays the "Hotelling price" directly to the insurance company $\left(\tau+C_{m}\right)$ plus the transportation cost for being located at a distance $1 / 2$ from the insurer $(\tau / 2)$.

16. Assumption (A) still guarantees that every customer buys the policy at equilibrium.

17. The variance of average cross subsidies without discrimination is $\operatorname{Var}\left(q^{n, n}\right)=\theta^{2}\left(\alpha_{h}-\alpha_{l}\right)^{2} s_{h}\left(1-s_{h}\right)$ and with discrimination is $\operatorname{Var}\left(q^{d, d}\right)=\theta^{2}\left(\alpha_{h}-\alpha_{l}\right)^{2} y^{2}(1-y)^{2} /\left[s_{h}\left(1-s_{h}\right)\right]$, so that the variance with discrimination is lower than without discrimination since $y(1-y)<s_{h}\left(1-s_{h}\right)$.

18. In the proof, available from the authors, we also show some other interesting properties of the asymmetric case: (a) the discriminatory firm's problem can be decomposed into choosing the weighted average of the two discriminatory prices and their difference when the rival does not discriminate, (b) a firm's average best reply to the rival's average price is not altered by the own ability or by the rival's ability to price discriminate, (c) as a result equilibrium average prices are unaffected by firms' ability to discriminate, (d) while prices do not change on average, a firm obtains strictly higher profits when its rival does not discriminate: in fact, the discriminating firm, while keeping the same average price, can also control the difference between its prices.

19. Recall that a type $t$ enjoys a gross surplus $V_{t}=\alpha_{t}$ from travelling.

20. For a thorough discussion of this approach see Hoy and Lambert [2000]. They suggest that a measure of inequity should belong to a "generalized entropy" family that satisfies a "principle of trasfers". This states that inequity should increase by shifting some inequity from a less to a more discriminated individual. Within this family, they propose to concentrate on the relative ratio $r=P / C$ of prices $P$ over costs $C$ rather than the absolute square $(P-C)^{2}$ as done by Schmalensee. In particular, they suggest the mean logarithmic variation, $\ln [\mathrm{E}(r)]-\mathrm{E}[\ln (r)]$, as a plausible functional form of inequity. We have run our calculations also using the mean logarithmic variation without affecting our results qualitatively.

21. In the examples below we set $w=1 / 2$ which also implies $s_{h}=1 / 2$. In this way aggregate risk does not vary with $y$, explaining why inequity does not vary with $y$ in the no-discrimination case in figure 2 . If $w \neq$ $1 / 2$, then $I^{n}=\tau^{2}+s_{h}\left(1-s_{h}\right) \Delta^{2}$ that decreases with $y$ when $y>1 / 2$. However, the behaviour of the curves would not be qualitatively affected.

22. The notion of efficiency would have to be reconsidered in the presence of externalities such as congestion and accident externalities; see Vickrey [1968] and Edlin [2003]. In the 1998 the U.S. Environmental Protection Agency sponsored an effort to examine the criticism and concerns expressed about Pay-at-the-Pump (PATP) auto insurance and explore the reformulation of PATP, taking into account these concerns.

23. This differs from previous results in the insurance literature that show that the use of costless classification results in Pareto improvements under perfect competition [Crocker and Snow, 1986; Crocker and Snow, 1992]. These models assume primitives that are very different from ours, e.g. they consider the use of deductibles to improve the adverse selection problem among risk-averse agents, or they deal with signalling where adverse selection can arise. The efficiency properties of categorization in our model do not cover these issues. Efficiency in our model is only related to ex post consumption ("miles driven").

24. For instance, it would be interesting to analyse the role of categorization in a dynamic setting $\grave{a}$ la Ania, Troger and Wambach [2002] where firms are limited in each period in their ability to design contracts.

25. Some countries explicitly recognise this in their regulations. For instance, California requires insurance companies to take into account consumption choices in their policies, while still allowing for other types of classification (such as driving experience). Classification based on religion and race is explicitly banned.

26. As in figure 2, we set $w=1 / 2$, which also implies $s_{h}=1 / 2$. From Eq. (5) it is then clear that the equilibrium uniform price is not affected by $y$. These observations also explain why $I^{n}$ does not vary with $y$ in figure 3(b). If $w \neq 1 / 2$, then $I^{n}$ would not be constant any more; however, the relative behaviour of the curves would not be qualitatively affected. The other parameter values used in the figures are: $\alpha_{h}=50, \alpha_{l}=10, \tau=1$, $\theta=0.1$.

27. $I^{v}, V^{v}$ and $H^{v}$ correspond to $I^{n}, V^{n}$ and $H^{n}$ in figure $3(\mathrm{c})$, while $I^{f}$ corresponds to $I^{n}$ in figure 2. 
28. Internal Market Commissioner Frits Bolkestein said (28/2/2001) that "insurance companies should be entirely free to set their scales of premiums, so that drivers can choose the most advantageous offer. Our intention is in no way to scrap the no-claims bonus system for differentiating between good and bad drivers, but to leave insurance companies free to choose the way in which they reward good drivers through lower premiums". Belgium and Finland responded to the Commission by abolishing the mandatory no-claims bonus system; on the other hand France and Luxembourg have been referred to the Court of Justice (21/3/2002).

29. "Rate regulation and other regulatory issues", Insurance Information Institute Report, April 2004.

30. A report from the UK government's independent transport advisers suggested in 2003 to use GPS technologies to charge drivers for journeys on Britain's most congested roads according to the level of congestion. The main objective would be to reduce congestion and pollution. The technology, if fitted to every car, could also be used to catch speeding drivers or by insurance companies to charge variable pricing.

\section{References}

ANIA, A., TROGER, T., and WAMBACH A. [2002]: "An Evolutionary Analysis of Insurance Markets with Adverse Selection," Games and Economic Behavior, 40, 153-184.

ARMSTRONG, M. and VICKERS, J. [2001]: "Competitive Price Discrimination," RAND Journal of Economics, 32, 579-605.

BOND, ERIC W. and CROCKER KEITH J. [1991]: "Smoking, Skydiving and Knitting: The Endogenous Categorization of Risk in Insurance Markets with Asymmetric Information,” Journal of Political Economy, 99, 177-200.

CROCKER, KEITH J. and SNOW, A. [1986]: "The Efficiency Effects of Categorical Discrimination in the Insurance Industry,” Journal of Political Economy, 94, 321-344.

CROCKER, KEITH J. and SNOW, A. [1992]: "The Social Value of Hidden Information in Adverse Selection Economies," Journal of Public Economics, 48, 317-347.

CROCKER, KEITH J. and SNOW, A. [2000]: "The Theory of Risk Classification," in Handbook of Insurance, Georges Dionne (Ed.), Boston, MA, Kluwer Academic Publisher.

EDLIN, AARON S. [2003]: "Per-mile Premiums for Auto Insurance," in Economics for an Imperfect World: Essays In Honor Joseph Stiglitz, Richard Arnott, Bruce Greenwald, Ravi Kanbur, and Barry Nalebuff (Eds.), MIT Press, Cambridge.

HOY, MICHAEL [1982]: “Categorizing Risks in The Insurance Industry,” Quarterly Journal of Economics, 97, 321-336.

HOY, M. and LAMBERT, P. [2000]: "Genetic Screening and Price Discrimination in Insurance Markets," The Geneva Papers on Risk and Insurance: Theory, 25, 103-120.

HOY, M. [1989]: “The Value of Screening Mechanisms Under Alternative Insurance Possibilities," Journal of Public Economics, 39, 177-206.

KAVALEC, C. and WOODS J. [1999]: “Toward Marginal Cost Pricing of Accident Risk: The Energy, Travel and Welfare Impacts of Pay-at-the-Pump Auto Insurance,” Energy Policy, 27, 331-342.

KHAZZOOM, DANIEL J. [2000]: "Pay at the Pump (PATP) Auto Insurance: Criticism and Proposed Modifications," Journal of Insurance Regulation, 18, 448-496.

LITMAN, TODD [2001]: "Distance-Based Vehicle Insurance: Feasibility, Costs and Benefits," Comprehensive Technical Report, Victoria Transport Policy Institute, Victoria, British Columbia.

REA, SAMUEL A. [1992]: "Insurance Classification and Social Welfare," in Contributions to Insurance Economics, Georges Dionne (Ed.), Boston, MA, Kluwer Academic Publisher.

ROCHET, JEAN-CHARLES and STOLE, LARS, A. [2003]: "The Economics of Multidimensional Screening," in Advances in Economics and Econometrics, Theory and Applications-8thWorld Congress of the Econometric Society, Mathias Dewatripont, Lars P. Hansen and Stephen Turnovsky (Eds.), Cambridge University Press, Cambridge.

SCHMALENSEE, R. [1984]: "Imperfect Information and the Equitability of Competitive Prices," Quarterly Journal of Economics, 99, 441-460.

SCHOORENS, GEERT [1999]: "Legal Limits to Risk Classification in a European Union Context," Paper Presented at the 8th Joint Conference EALE-Geneva Association, Rotterdam. 
STOLE, LARS A. [2001]: "Price Discrimination in Competitive Environments," in Handbook of Industrial Organization, Mark Armstrong and Robert H. Porter (Eds.), North-Holland, Amsterdam (forthcoming) Vol. III.

VICKREY, WILLIAM [1968]: “Automobile Accidents, Tort Law, Externalities and Insurance: An Economist's Critique," Law and Contemporary Problems, 33, 464-487.

WENZEL, T. [1995]: “Analysis of National Pay-As-You-Drive Insurance Systems and Other Variable Charges," LBL-37321, Energy and Environment Division, Lawrence Berkeley National Laboratory (CA). 